\title{
Significance of Music Technology to Huacun Dance Choreography in Intangible Cultural Heritage
}

\author{
Wan Zhanzhan ${ }^{1, *}$, Li Jia ${ }^{2}$ \\ ${ }^{1}$ Zhan Yi Dance Training School, Yanzhou District, Jining, Shandong, China \\ ${ }^{2}$ College of Music, Shanxi Normal University, Shanxi, China \\ *Corresponding author
}

Keywords: intangible cultural heritage, flower stick dance, music technology, dance creation

\begin{abstract}
With the rapid development of modern music technology, the ever-changing music technology has a subtle influence on the structure and arrangement of dance creation and choreography in the process of dance creation and choreography. Take the intangible traditional Huazhu dance in Yanzhou District, Jining City, Shandong Province. Our original traditional choreography is not combined with modern music technology, so the old choreography can only be based on the inheritance of old folk artists and folk selfentertainment. The old music has no innovation, but it is now combined with modern MIDI technology. With development, breakthroughs and innovations have been made in the creation and arrangement of Huacun Dance, which has added a touch of the new color to our intangible cultural heritage dance.
\end{abstract}

\section{Overview of Yanzhou Intangible Cultural Heritage Dance Huagun Dance}

The Huacun Dance in Yanzhou District, Jining City, Shandong Province, is an intangible cultural heritage. The historical prototype is also called "playing the Huacun" and "Overlord Whip." Incorporating the artistic characteristics of "Dalianxiang" or "Overlord Whip," which has been passed down to this day, a unique folk art system has been formed. From the folk songs of Huacun Dance that have been passed down to this day, we can know that "Playing Huacun" has a history of nearly a hundred years in the southern Shandong area. In the context of historical disasters, the poor people of Yanzhou, After becoming victims begging along the street, gradually changed from begging to "sing the door" and used the "flower stick" to beat the festival, developing into the "flower stick dance." In the 1990s, the Yanzhou Cultural Department systematically organized the Huacun Dance, combined with the characteristics of the modern era, and added new musical elements and performance routines based on the original dance charm so that the dance combines contemporary music elements with auspicious elements. The cheerful mood is the main form of folk art that extols the remarkable life and expresses happiness. The current Huacun dance has a lively rhythm and strong jumping ability. The melody is sometimes subtle and delicate, sometimes bold and unrestrained. Under the music and dance conveys the Chinese nation's optimistic attitude and uplifting spirit in the face of difficulties and setbacks, giving people a beautiful look of artistic enjoyment and spiritual inspiration. 


\section{The application of music technology to the creation and choreography of Yanzhou}

intangible cultural heritage flower stick dance

Music and rhythm are the souls of dance, and the moral and connotation of dance need to be expressed and output from the background of music. Through various unpredictable forms of music, the creation and editing of dance have also been broken and innovative. With the development of MIDI technology in music, the innovation of music forms also promotes the transformation and innovation of dance. Therefore, the combination of MIDI technology and dance creation is the inevitable result of artistic development.

With the rapid development of modern music technology in dance creation and choreography, the ever-changing music technology has subtly affected the structure and arrangement of dance creation and choreography. The intangible cultural heritage dance flower stick dance in Yanzhou District, Jining, Shandong has gone through years of historical inheritance. Today, the music of Huacun Dance has evolved from the old form of singing along the street, singing and dancing with fixed repertoire, into a new style of music combined with various MIDI music techniques such as selected orchestration, combined melody, and sound field control. The choreography of stick dance brings innovation and innovation. Our original traditional flower stick dance was not combined with modern music technology, so the original flower stick dance was based on the inheritance of old folk artists and folk self-entertainment. The music style is outdated, and there is no innovation, but now it is combined with modern music. The development of technology and the personalization of music creation under MIDI production has brought substantial changes to the creation of personalized dance of Huacun Dance. The creation of Huacun Dance has made breakthroughs and innovations, adding to our intangible cultural heritage dance. A new model of color.

Modern flower stick dance uses suona, erhu, clapper, bamboo flute, drums, and other national instruments in the music orchestration, which combines the flower stick tune of hawking and the original beggar, and various sound effects are incorporated into the flower stick tune. The effect of MIDI making synthesizers vividly shows the rich flavor of southwestern Shandong and the folk customs of northern Shandong.

Dance choreographers need creative inspiration in the creative process. Music production allows choreographers to have imaginative space for their choreography ideas and dance structure and can request music production's specific process and details according to their aesthetic ideas. In Yanzhou Intangible Cultural Heritage Dance, Yin Yong, the choreographer, and director of the Yanzhou District Cultural Center, Jining City, Shandong Province, has unique insights into the history and inheritance of Yanzhou Intangible Cultural Heritage Dance. I interviewed the choreographer of Yanzhou Intangible Cultural Heritage Dance. He believes that intangible cultural heritage dance choreography should combine the connotation and intention of intangible cultural heritage. In the production of music, the beginning of the Yanzhou flower stick tune deeply let us understand that in ancient times, the people of Yanzhou were plagued by disasters, and the victims were begging along the street. Historically, the call of begging and begging gradually changed as "singing the door," and singing the door is the Huacun tune of modern Yanzhou Huacun Dance. The actual sound effects collected through electronic sound effects recording and live collection, mixed with a part of the melody accompaniment of folk music such as suona, erhu, directly reflect the authenticity of history and have a strong sense of the scene achieving the musical effect expected by the director. It can be seen that in the organic integration of music production and dance, the Yanzhou Intangible Cultural Heritage Flower Stick Dance has demonstrated the tension and momentum of the dance and is inspiring. 
Table 1. Interview target and interview information table.

\begin{tabular}{|l|l|l|l|l|l|}
\hline Interviewee & Gender & Age & \multicolumn{1}{|c|}{ Job Position } & $\begin{array}{c}\text { Interview } \\
\text { Time }\end{array}$ & \multicolumn{1}{|c|}{$\begin{array}{c}\text { Interview } \\
\text { Location }\end{array}$} \\
\hline Yin Yong & male & 46 & Choreographer & 72 minutes & Cultural hall \\
\hline Li Dan & male & 53 & curator & 75 minutes & Cultural hall \\
\hline Xu Yueqiang & male & 45 & Deputy Director & 70 minutes & Cultural hall \\
\hline Teacher Li & Female & 42 & Choreographer & 65 minutes & Cultural hall \\
\hline
\end{tabular}

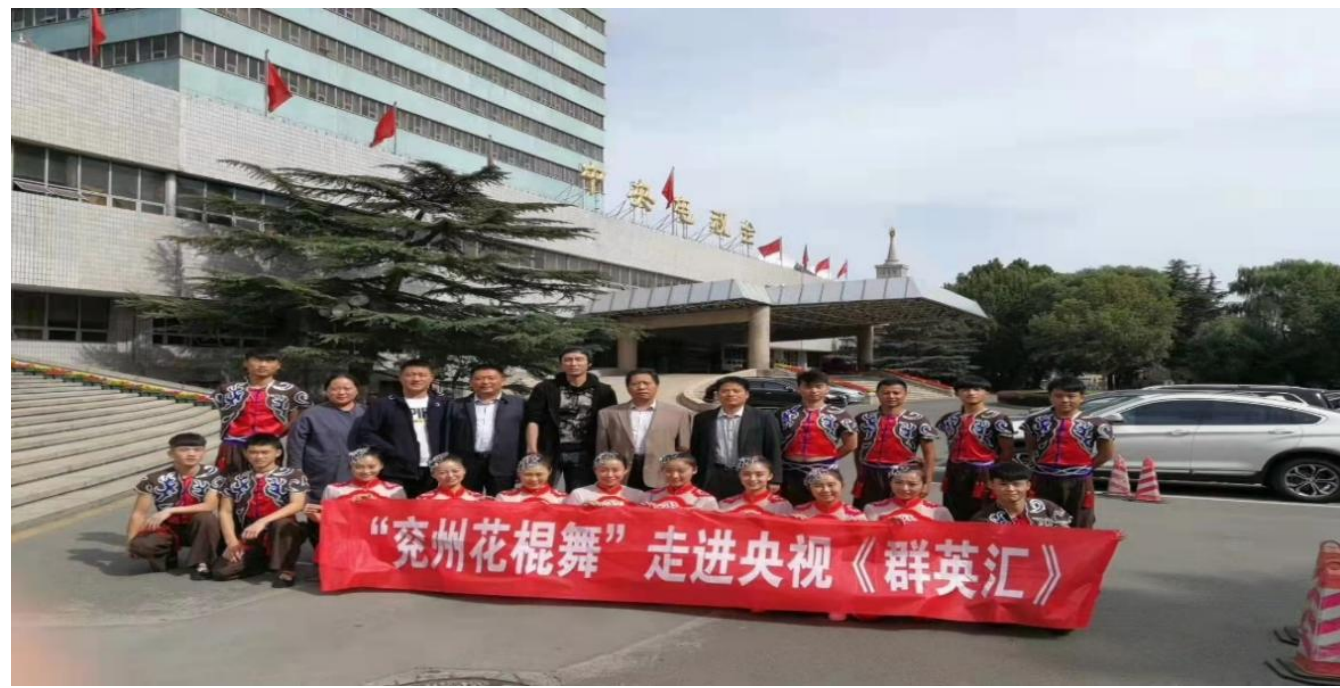

Figure 1. It shows the new compilation of Yanzhou Intangible Cultural Heritage Flower Stick Dance was invited by China Central Television to participate in the recording of "Queen Yinghui"

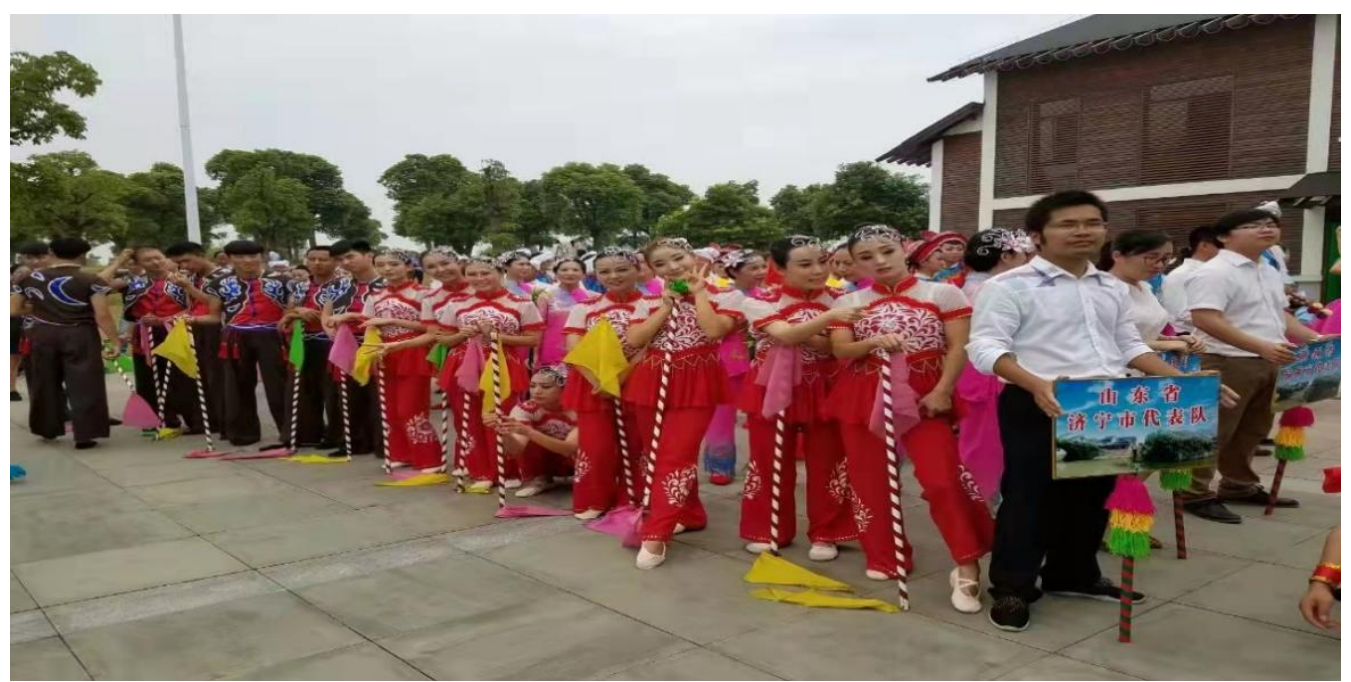

Figure 2. It shows the new composition of Yanzhou Intangible Cultural Heritage Huacun Dance participating in the Luzhi National Evening Box Competition

MIDI production combines human voice effects and music orchestration and uses synthesis technology to produce the Yanzhou Huacun tune with the characteristics of the Yanzhou region. It is used for the beginning of the dance. The Yanzhou Huacun tune makes the beginning of the Huacun dance very distinctive. Ethnic style. After the magnificent flower stick tune is over, the lyrical and delicate suona music chants. Under the background of the main tune of suona, the melody delay, crescendo, and fading of music production are used to change the rhythm of sound 
effects. The next Han girls swayed the flower sticks to appear on the stage. The dance choreographer got new inspiration through the rhythm change after music technology production. After the intense flower stick tune instantly weakened into a lyrical female flower stick dance section. It is evident here. It is a manifestation of music production to choreography and scene choreography.

In addition to changes in rhythm and speed, MIDI music production can also appropriately adjust the intensity of the music, which is also a new inspiration for the choreography of the flower stick dance. A sonorous piece of music is synthesized through MIDI sound effects and integrated into drum beats, vibrato, and other sound effects. Music orchestration such as clapper and suona erhu was added, and the choreography of Hua Gun Dance was also processed with the intensity and melody of the music. For example, in the first stage of the dance climax, the intensity of the music was gradually strengthened, and the dance movements also consisted of a single hand. Beating the flower stick is strengthened to the collision with the body. The flower stick hits the shoulders, waist, kicks, elbows, kicks, and feet interlaced with each other. The intensity of the music is consistent with the external courage and courage of the actors hitting the flower sticks. The fusion of frustrating and powerful movements shows that the ancient Chinese people have perseverance that is not afraid of suffering and fearlessness.

When the dance enters the climax part, the choreographer uses music production techniques, music melody sound effects, and other music production techniques to push the dance to its climax. Based on the original flower stick dance, techniques such as jumping, turning, turning, and spinning is incorporated to make the dance. The style is diversified, and this innovation is also a prominent feature of modern Huacun Dance. Through the dynamic and powerful rhythmic music characteristics, the performers can easily show their superb skills. The choreographer, director, and creative conception combine the dance with technology and art. Straightforward emotions can be expressed. The editing and production techniques of music have played a finishing touch to the dance skills such as "cross jump," "rotator," and "tiger flapping," changing the audience's visual image of the inherent Huacang dance. There are also innovations in dance-style routines.

At the end of the dance, the actors and actresses gathered in the middle of the stage after a series of technical movements. The movement texture slowly slowed down to a slow rhythm when the two people hit the flower sticks. The lyrical suona melody matched, and there was a clear space. The field effect makes the dance pave the way before the end, and the editing of music embodies a critical role here. The repeated melody repetition in MIDI production gave new creative inspiration to the structure and action language of the dance. The action vocabulary of repeated waist beating, foot beating, and men and women repeatedly beating the flower cudgel is the choreographer's use of music: the repetitive musical melody, rhythm, and musical mood created during the production. At the end of the dance, after the dance of the two men and women playing the flower sticks, the music sound effects incorporate the sound of singing and laughing electronic sound effects, which adds to the performance of the dance form even more. Passionate and cheerful, a dancing mood that sends a good harvest and sings a good life.

\section{The practicality of music technology for dance creation}

As a comprehensive dance art, music occupies a significant position. Only with complete matching music can an excellent dance work. Before music technology, most dance choreography was based on original songs or various music. The combination of elements is a patchwork pattern to create dances, and the development of music technology has broken the pattern of only dance music sources. At the same time, the sound effects, editing, and sound field techniques in MIDI production technology are more and more accepted and applied by dance choreographers. Dance 
choreographers can use music technology, and original dance music can be processed with different effects through music technology such as tone color, volume, sound effects, dynamics, panning, and effects. This is an excellent boon for modern dance music creators to achieve the final result of one's choreography and thinking structure. Music technology dramatically reduces the cost of dance creation and arrangement and does not require labor and resources, such as the flower stick dance. When choreographing, the Chinese choreographer pursues the musical effect melody of the ensemble of folk music instruments. Before the birth of music technology, we need to mobilize all folk music players, erhu, suona, gongs and drums, guzheng, pipa, etc., to perform and record together. When entering the recording studio, the synthesis of music is recorded in a single, but now the synthesis of music technology does not need to mobilize significant band performances and single recording in the recording studio; only the computer keyboard can complete the synthesis and storage of the sound of each track in the sequencer.

There are many special effects in dance creation. It is very troublesome to record with natural sound. However, after music MIDI is produced, all the sound and timbre effects in nature can be produced through MIDI music technology. Many dance choreographers have also produced the imitation of electronic sound effects. Adopted, the Huacun dance has the sound effect of the Huacun strike, which is also produced through music. At present, many large-scale dance dramas and dance poems in China have also been tried, from the selection of orchestration, the arrangement of melody, and the setting of sound field effects. And so on, it can demonstrate the efficient application of music technology in choreography.

\section{Summary}

In summary, as the Yanzhou intangible cultural heritage dance Huacun Dance, the modern choreographer and the new school created and choreographed with music technology have enabled Huacun Dance to retain the authenticity, integrity, and inheritance of the original intangible cultural heritage. The dance structure and performance form have been innovative and diversified, showing the progress of the masses of the people in Yanzhou, Jining, Shandong in their artistic pursuit and attainments. The development and application of music technology have brought far-reaching positive effects on the choreography of Huacun Dance. They have also realized the artistic inheritance of the excellent traditional culture of the Chinese nation.

\section{References}

[1] Li Zhuoran. The role of MIDI production technology in dance creation [J]. Popular Literature. Art and Design. Music Department of Guilin Teachers College. 541001

[2] Wei, Y.; Yan, H.; Bie, R.; Wang, S.; Sun, L. Performance monitoring and evaluation in dance teaching with mobile sensing technology. Pers. Ubiquitous Comput. 2014, 18, 1929-1939.

[3] Wang, Y.; Baciu, G. Human motion estimation from monocular image sequence based on cross-entropy regularization. Pattern Recognit. Lett. 2003, 24, 315-325

[4] Tong, M.; Liu, Y.; Huang, T.S. 3D human model and joint parameter estimation from monocular image. Pattern Recognit. Lett. 2007, 28, 797-805.

[5] Luo, W.; Yamasaki, T.; Aizawa, K. Cooperative estimation of human motion and surfaces using multiview videos. Comput. Vis. Image Underst. 2013, 117, 1560-1574.

[6] Min, J.; Liu, H.; Chai, J. Synthesis and Editing of Personalized Stylistic Human Motion. In Proceedings of the 2010 ACM SIGGRAPH Symposium on Interactive 3D Graphics and Games (I3D'10), Washington, DC, USA, 19-21 February 2010; ACM: New York, NY, USA, 2010. 84.

[7] Cho, K.; Chen, X. Classifying and Visualizing Motion Capture Sequences using Deep Neural Networks. In Proceedings of the 9th International Conference on Computer Vision Theory and Applications (VISAPP 2014), Lisbon, Portugal, 5-8 January 2014. 